\section{THE MOST FAVORED NATIONS MODEL INTERIM FINAL RULE IS FATALLY FLAWED AND MUST BE RESCINDED-YET THE PROBLEM IT ADDRESSES DEMANDS A SOLUTION}

The Most Favored Nations (MFN) Model Interim Final Rule that was posted November 20 for implementation January 1, 2021, ${ }^{1}$ poses acute and long-term dangers for Medicare beneficiaries and for cancer care providers.

The rule imposes international reference pricing (IRP) for drugs, referencing nations within the Organisation for Economic Co-operation and Development with at least $60 \%$ gross domestic product (GDP) relative to the United States, adjusting IRP for relative GDP differences, and replaces the current percentage add-on with a fixed-fee add-on. The rule's initial targets are the top 50 (by dollars) Part B injectables, representing about $75 \%$ of 2019 annual allowed charges for separately payable drugs.

The rule creates a 7-year nationwide pilot, mandatory for almost all Medicare providers. In the first year, the MFN price is a blend of $75 \%$ of average sales price (ASP) and 25\% of IRP, with blend adjusting annually until $100 \%$ IRP is achieved in the fourth year, continuing through the seventh year.

The rule poses an acute danger because there is insufficient time to implementation, including intervention during the Thanksgiving and Christmas holidays and the COVID 19 pandemic, for stakeholders to adjust and for education. Chaos and limited access to these drugs are likely.

The rule poses a long-term danger to Medicare beneficiaries and to cancer providers. Analysis by the Centers for Medicare \& Medicaid Services (CMS) Office of the Actuary (OACT) projects that $9 \%-19 \%$ of drugs will be inaccessible because some manufacturers will not sell products at MFN prices. Unlike OACT's analysis, the Assistant Secretary for Planning and Evaluation's (ASPE) analysis, also cited in the rule, assumes, without evidence, that manufacturers will sell at MFN prices.

The rule changes provider's add-on payment to a flat $\$ 148.73$ per drug, inflation adjusted annually, resulting in OACT's projection that drug revenues for hematology/oncology, medical oncology, and gynecological oncology practices will decrease $-8 \%,-13 \%$, and $-33 \%$, respectively. Because drugs comprise a significant portion of revenue for these practices, and because Medicare beneficiaries comprise a large fraction of patients, reductions will be difficult to sustain. Yet the rule provides a windfall for ophthalmology, urology, cardiology, orthopedic surgery, and endocrinology practices, which will see their add-on payments increase $+140 \%$, $+143 \%,+1,284 \%,+794 \%$, and $+194 \%$, respectively.

ASPE's analysis states, without evidence, that there are therapeutically comparable substitutes for drugs from manufacturers unwilling to drop sales prices to meet MFN prices. Not addressed are negative clinical implications should ASPE be wrong.

The rule provides no fail-safe access for Medicare beneficiary access to Part B drugs, stating that "should an eligible provider or supplier be unable to offer access to included drugs, beneficiaries will be left with several options. They could seek access to the drugs by traveling to an excluded provider or supplier, access the drugs through a $340 \mathrm{~B}$ provider in the model, or forgo access." An appeals process is available only once "an MFN Model drug is furnished by an MFN participant to a beneficiary and a claim is submitted and processed for payment."1

A statement posted on November 24 to the American Society of Clinical Oncology website condemned this rule in a statement titled "Most Favored Nation Model is misguided and will decrease access to cancer care," urging CMS to withdraw the rule. ${ }^{2}$

The United States faces high and rapidly increasing drug costs, particularly with respect to biologicals and injectables, but the rule's approach to this problem is dangerous. It would be safer to have a limited scope CMS Innovation Center pilot. But pressure is building for a comprehensive solution, such as, perhaps, congressional action enabling Medicare direct contracting with pharmaceutical manufacturers.

Might pharmaceutical manufacturers, acting together, offer an alternative to put a lid on drug prices and price trends, thereby reducing pressure for action that may irreversibly change U.S. drug pricing?

Elan Rubinstein, PharmD, MPH EB Rubinstein Associates

Oak Park, CA

elan.b.rubinstein@gmail.com

\section{DISCLOSURES}

No funding supported the writing of this letter. The author has nothing to disclose.

\section{REFERENCES}

1. Centers for Medicare \& Medicaid Services. Interim Final Rule (IFC). CMS5528-IFC. Most Favored Nation (MFN) Model. November 18, 2020. Accessed January 16, 2021. https://innovation.cms. gov/media/document/mfn-ifc-rule

2. Bertagnolli M. Most Favored Nations Model is misguided and will decrease access to cancer care. American Society of Clinical Oncology. November 24, 2020. Accessed January 16, 2021. https://www.asco.org/aboutasco/press-center/news-releases/ most-favored-nation-model-misguidedand-will-decrease-access 